\title{
Functionalized Poly(ether ether ketone) Analogues via Reactivity Ratio Controlled Polycondensation
}

This manuscript is dedicated to Professor Krzysztof Matyjaszewski on the occasion of his $65^{\text {th }}$ Birthday.

Godfred Boakye, Rachel Stuck, Kara Geremia, Robert J. Wehrle, R. Hunter Cooke III, Shravanthi Raghavapuram and Eric Fossum*

Department of Chemistry

Wright State University

3640 Colonel Glenn Hwy.

Dayton, $\mathrm{OH} 45435$

Email: eric.fossum@,wright.edu

Keywords: reactivity ratios; nucleophilic aromatic substitution; meta activation; functional groups; structure-property relationships

*Correspondence to: Eric Fossum, Department of Chemistry, Wright State University, 202 Oelman Hall, 3640 Colonel Glenn Highway, Dayton, OH USA 45435. Email:

eric.fossum@wright.edu 


\begin{abstract}
A route for the introduction of functional groups to poly(ether ether ketone) analogues, via a reactivity ratio controlled polycondensation process, has been developed. The reactivity differences, toward nucleophilic aromatic substitution reactions, of the three electrophilic sites in 3,4',5-trifluorobenzophenone, $\mathbf{1}$, affords the opportunity to prepare functionalized $\mathrm{B}_{2}$-type monomers in situ, followed by polycondensation with the appropriate bisphenol to prepare the corresponding linear polymer. The reactivity differences in $\mathbf{1}$ were probed via a combination of ${ }^{13} \mathrm{C}$ and ${ }^{19} \mathrm{~F}$ NMR spectroscopy along with model reactions using $m$-cresol as the nucleophile. Reaction of 1 with 1.03 molar equivalents of a series of phenols provided the desired $B_{2}$-type monomers in high selectivity. The $\mathrm{B}_{2}$-type monomers were then converted to the linear polymers by reaction with Bisphenol-A and their structures were confirmed via NMR spectroscopy. The thermal properties were evaluated by a combination of thermogravimetric analysis and differential scanning calorimetry.
\end{abstract}




\section{Introduction}

Poly(arylene ether)s, PAE's, are a class of engineering thermoplastics composed of aromatic rings linked together via ether bonds. The simplest PAE is poly( $p$-phenylene oxide) although it is not commercially available. ${ }^{1}$ The more well known poly(2,6-dimethylphenylene oxide) is commonly referred to as PPO and is readily available. ${ }^{1}$ Two of the more widely utilized engineering thermoplastic materials are poly(ether ether ketone), PEEK, ${ }^{2,3}$ and poly(arylene ether sulfone)s, PAES. ${ }^{4}$ PAE's are renowned for their thermal and chemical stability making them suitable for a wide variety of end uses. PEEK is a highly crystalline material while PAES systems are completely amorphous.

With the exception of PPO, and its derivatives, which are synthesized via oxidative coupling processes, ${ }^{1}$ the synthesis of poly(arylene ether)s, PAEs, is typically achieved through nucleophilic aromatic substitution, NAS, reactions of activated aryl halides with phenolate ions. ${ }^{4,5}$ A wide variety of activating groups have been employed such as the strongly electron withdrawing sulfonyl, ${ }^{5-8}$ - carbonyl, ${ }^{2,9,10}$ and phosphoryl groups. ${ }^{11-16}$ In all of these cases, the activating group is located in the para position relative to the aryl halide, which activates the electrophilic position by decreasing the electron density at the ipso carbon atom. The activating group also serves to stabilize the anionic intermediate, known as a Meisenheimer complex. In most cases, the electron-withdrawing group, EWG, becomes an integral part of the backbone. One of the long sought after goals in PAE chemistry is the facile introduction of functional groups onto these engineering thermoplastics to modify their properties without sacrificing the backbone. Currently, the NAS conditions required for the synthesis of many PAE's limits access to the desired functional group containing materials. 
We have been developing methodology, based on meta-activated NAS reactions of 3,5difluoro aromatic systems as a route to the geometric isomers of typical PAE systems. The activating groups, including sulfone, ${ }^{17}$ ketone, ${ }^{18}$ phosphoryl, ${ }^{19}$ and sulfonamide, ${ }^{20}$ are incorporated pendent to the backbone and provide an excellent site for the introduction of functional groups, without disrupting the backbone of the polymer.

\subsection{Functionalized PEEK Derivatives}

The highly crystalline nature of PEEK has been a severe hindrance to the incorporation of functional groups onto its backbone. The synthesis of functionalized PEEK systems generally requires the multistep synthesis of specialty monomers for the "pre" method or the introduction of functional groups directly onto the backbone in a "post" polymerization modification process. The incorporation of functional groups relies heavily on the electron-rich bisphenol component. For example, the incorporation of an aliphatic carboxylic acid, via the corresponding acidcontaining bisphenol, was reported by Ritter. ${ }^{21}$ A post polymerization sulfonation reaction can introduce the corresponding sulfonic acid groups on the electron rich rings, but also carries the risk of cross-linking. ${ }^{22}$

A combination approach has been applied by Roovers et al, in which methyl hydroquinone was used as the bisphenol, followed by subsequent conversion to the bromo methyl group. ${ }^{23}$ In turn the bromo methyl group provides access to a host of carbonyl containing functional groups. Other "pre" methodologies have led to PEEKs bearing tertiary amino, ${ }^{24}$ amino (aniline) ${ }^{25}$ and sulfonic acid groups, ${ }^{9,26}$ while a post polymerization reduction of the carbonyl groups present in the benzophenone moiety results in the formation of secondary alcohols. 27,28 Typically, when the functional groups are present or the specialty monomer is incorporated, the semi-crystalline nature of PEEK is lost. 
As such, a methodology that affords the possibility of introducing functionality while maintaining some level of crystallinity would provide a significant advancement to the field. We have previously described the preparation of semi-crystalline, soluble PEEK derivatives based on 3,5-difluorobenzophenone. ${ }^{29}$ The result is a PAE-type material that carries a pendent benzoyl group, which is an ideal site for the introduction of functional groups.

\subsection{Reactivity Ratio Controlled Polycondensation, RRCP}

During the course of investigations dealing with the synthesis of hyperbranched PAEs from $\mathrm{A}_{2}+\mathrm{B}_{3}$ systems we observed considerable differences in the reactivity of the three aryl fluoride moieties in some $\mathrm{B}_{3}$ monomers, such as 3,5,4'-trifluorobenzophenone, $\mathbf{1}$, as illustrated in Scheme 1. ${ }^{30}$ The para-fluoride was considerably more reactive than the meta-positions and, while initially the two meta-fluorides are of equivalent reactivity, upon reaction of one metafluoride, the last one became significantly less reactive.

If the differences in reactivity are sufficient, a $\mathrm{B}_{3}$-type monomer, more aptly described as a BB'B" monomer, provides the opportunity to install a functional group in situ, followed by polymerization to the desired, linear poly(arylene ether). This report will describe our initial efforts to prepare functional PEEK analogues via a "one-pot", reactivity ratio controlled polycondensation (RRCP) process, based on $\mathbf{1}$. 

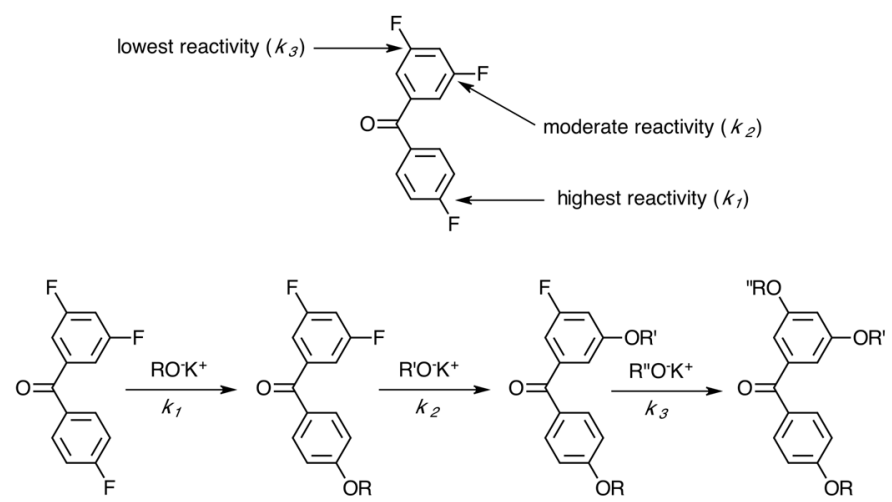

Scheme 1. Reactivity ratios of 3,5,4'-trifluorobenzophenone, 1 , a potential $\mathrm{B}_{3}$ (BB'B') type monomer for the synthesis of functional poly(arylene ether)s, PAE, via a reactivity ratio controlled polycondensation, RRCP.

\section{Experimental}

\subsection{Materials}

All reactions were carried out under a nitrogen atmosphere. Reagent-grade anhydrous potassium carbonate powder $\left(\mathrm{K}_{2} \mathrm{CO}_{3}\right)$ and calcium chloride $\left(\mathrm{CaCl}_{2}\right)$ were dried at $130{ }^{\circ} \mathrm{C}$ in an oven before use. Anhydrous aluminium chloride $\left(\mathrm{AlCl}_{3}\right)$, 4-tert-butyl phenol, 3-aminophenol, ethyl-4hydroxybenzoate, and 4-methoxyphenol were purchased from Sigma Aldrich Chemical Co. and used as received. Bisphenol-A was purchased from Sigma Aldrich Chemical Co., recrystallized from toluene and dried under vacuum prior to use. $N$-Methylpyrrolidinone (NMP) was purchased from Sigma Aldrich Chemical Co., dried and distilled over $\mathrm{CaH}_{2}$ under nitrogen prior to use. Phenol and $p$-cresol were purchased from Sigma Aldrich Chemical Co. and distilled under vacuum prior to use. 4-bromophenol was purchased from Sigma Aldrich Chemical Co., recrystallized from hexanes and dried under vacuum prior to use. Fluorobenzene and 3, 5difluorobenzoyl chloride were purchased from Oakwood Products and used as received. 


\subsection{Instrumentation}

GC/MS analyses were carried out using a Hewlett-Packard (HP) 6890 Series GC with auto injection and a HP 5973 Mass Selective Detector/Quadrupole system.

${ }^{1} \mathrm{H}$ and ${ }^{13} \mathrm{C}$ NMR spectra were acquired using an AVANCE $300 \mathrm{MHz}$ instrument operating at 300, and 75.5 MHz, respectively. Samples were dissolved in appropriate deuterated solvents (DMSO- $\mathrm{d}_{6}$ or $\left.\mathrm{CDCl}_{3}\right)$, at a concentration of $(\sim 30 \mathrm{mg} / 0.6 \mathrm{~mL}) .{ }^{19} \mathrm{~F}$ NMR spectra were obtained using a Bruker AVANCE $400 \mathrm{MHz}$ instrument operating at $376.5 \mathrm{MHz}$ using $10 \% \mathrm{CFCl}_{3}$ as an external standard with the instrument set relative to the lock signal.

Size Exclusion Chromatography (SEC) analysis was performed using a system consisting of a Viscotek Model 270 Dual Detector (viscometer and light scattering) and a Viscotek Model VE3580 refractive index detector. Two Polymer Laboratories $5 \mu \mathrm{m}$ PL gel Mixed C columns (heated to $35{ }^{\circ} \mathrm{C}$ ) were used with tetrahydrofuran $/ 5 \%(\mathrm{v} / \mathrm{v})$ acetic acid as the eluent and a GPCmax VE-2001 with pump operating at $1.0 \mathrm{~mL} /$ minute. Number average molecular weights, $\mathrm{M}_{\mathrm{n}}$, and the dispersity were determined with the RI signal (calibrated with polystyrene standards DSC and TGA analysis were carried out under nitrogen (or air) on TA Instruments DSC Q200 and TGA Q500, respectively, at a heating rate of $10^{\circ} \mathrm{C} / \mathrm{min}$. Melting points were determined on a MEL-TEMP apparatus and are uncorrected. Elemental analyses were obtained from Midwest Microlabs, Inc., Indianapolis, IN.

\subsection{Synthesis of 4', 3, 5-trifluorobenzophenone, 1}

In a $100 \mathrm{~mL}$ RB flask, equipped with an addition funnel, condenser, a stir bar, a nitrogen gas inlet and a $\mathrm{CaCl}_{2}$ drying tube were placed $9.10 \mathrm{~g}(68.0 \mathrm{mmol})$ of $\mathrm{AlCl}_{3}$ and $25 \mathrm{~mL}$ of fluorobenzene. 3,5-difluorobenzoylchloride $(6.5 \mathrm{~mL}, 55.0 \mathrm{mmol})$ was measured under a 
nitrogen blanket and added to the addition funnel containing $28 \mathrm{~mL}$ of fluorobenzene. The resulting mixture was added to the flask, drop wise, over 1 hour at room temperature and maintained with stirring for 24 hours. The reactant mixture was precipitated into an excess of acidified deionized water $(300 \mathrm{~mL})$ and extracted into chloroform $(150 \mathrm{~mL})$. The organic layer was washed three times with DI water, dried over $\mathrm{MgSO}_{4}$ and evaporated to dryness via the rotary evaporator followed by drying in vacuo to obtain $11.82 \mathrm{~g}(91 \%)$ of an off-white solid.

The crude product was recrystallized from ethanol and then from ethanol/water to afford $8.02 \mathrm{~g}$ (62\%) of white needle-like crystals with a melting point of $65-67{ }^{\circ} \mathrm{C} .{ }^{1} \mathbf{H}-\mathrm{NMR}(300 \mathrm{MHz}$, $\left.\mathrm{CDCl}_{3}, \delta\right): 7.10(\mathrm{tt}, J=8.5,2.4 \mathrm{~Hz}, 1 \mathrm{H}), 7.21-7.29(\mathrm{~m}, 2 \mathrm{H}), 7.30-7.38(\mathrm{~m}, 2 \mathrm{H}), 7.87-7.93(\mathrm{~m}$, 2H). ${ }^{13}$ C NMR (75.5 MHz, $\left.\mathrm{CDCl}_{3}, \delta\right): 107.7$ (t), 112.7 (dd), 115.8 (d), 132.6 (d), 132.6 (d), 140.4 (t), 162.7 (dd), 165.8 (d), 192.4 (t). Elemental Analysis: Calc. Anal. for $\mathrm{C}_{13} \mathrm{H}_{7} \mathrm{~F}_{3} \mathrm{O}: \mathrm{C}$, 66.11; H, 2.99; Found: C, 66.03; H, 2.87.

\subsection{General Procedure for the "Pre"-Functionalization of Compound 1 via "One-Pot",}

\section{Two-step Approach}

A typical "pre"-functionalization of compound $\mathbf{1}$ via "one-pot" approach will be described using phenol (3a). The model compounds in Scheme 2 were prepared in a similar fashion to Step 1.

Step 1: In a $10 \mathrm{~mL}$ R.B flask, equipped with a stir bar, condenser and a nitrogen gas inlet, were placed $0.236 \mathrm{~g}$ (1.00 mmol) of 4', 3, 5-trifluorobenzophenone (1), $0.097 \mathrm{~g}$ (1.03 $\mathrm{mmol})$ of phenol (3a), $1.6 \mathrm{~mL}$ of $N$-methylpyrrolidone (NMP) and $0.207 \mathrm{~g}(1.50 \mathrm{mmol})$ of potassium carbonate 
$\left(\mathrm{K}_{2} \mathrm{CO}_{3}\right)$. The reaction flask was immersed in a preheated oil bath and stirred vigorously at 110 ${ }^{\circ} \mathrm{C}$ until complete conversion to the desired mono-substituted product was achieved as evidenced by GC/MS analysis.

Step 2: Into the same reaction flask were added $0.228 \mathrm{~g}$ of Bisphenol-A (1.00 mmol), $0.415 \mathrm{~g}$ (3.00 mmol) of $\mathrm{K}_{2} \mathrm{CO}_{3}$. The reaction temperature was raised to $185^{\circ} \mathrm{C}$ and maintained for 24 hours. The reaction was cooled to room temperature, precipitated from acidified distilled water and isolated by vacuum filtration to afford $0.443 \mathrm{~g}(89 \%)$ of $4 \mathbf{a}$ as a beige colored solid. The solid was dissolved in THF, precipitated from water, filtered, and then reprecipitated from chloroform into a 1:1 mixture of hexane and isopropanol, isolated and dried to afford $0.349 \mathrm{~g} \mathrm{(70}$ $\%)$ of $4 \mathbf{a}$ as a beige solid.

${ }^{1} \mathbf{H}$ NMR $\left(\mathrm{CDCl}_{3}, \delta\right): 1.68(\mathrm{~s}, 6 \mathrm{H}) ; 6.88-7.40(\mathrm{~b}, 18 \mathrm{H}) ; 7.79-7.82(\mathrm{~b}, 2 \mathrm{H}) ;{ }^{13} \mathbf{C}$ NMR $\left(\mathrm{CDCl}_{3}, \delta\right)$ : $31.0,42.3,112.0,113.9,117.0,118.9,119.7,120.2,128.3,130.1,131.3,132.5,140.5,146.3$, 154.0, 155.4, 158.8, 161.9, 194.0.

4b (78 \%). ${ }^{1} \mathbf{H}$ NMR $\left(\mathrm{CDCl}_{3}, \delta\right): 1.67$ (s, 6H); $2.35(\mathrm{~s}, 3 \mathrm{H}) ; 6.87-7.28(\mathrm{~b}, 17) ; 7.79-7.81$ (b, 2H); ${ }^{13} \mathbf{C}$ NMR $\left(\mathrm{CDCl}_{3}, \delta\right): 21.4,31.0,42.3,112.1,113.8,117.0,117.2,118.9,120.8,125.5,128.3$, $129.7,131.2,132.5,140.1,140.5,146.3,154.0,155.7,158.8,162.0,194.0$.

4c (80 \%). ${ }^{1} \mathbf{H}$ NMR $\left(\mathrm{CDCl}_{3}, \delta\right): 1.68(\mathrm{~s}, 6 \mathrm{H}) ; 3.82(\mathrm{~s}, 3 \mathrm{H}) ; 6.81-7.28(\mathrm{~b}, 17 \mathrm{H}) ; 7.77-7.79(\mathrm{~b}, 2 \mathrm{H})$ ${ }^{13} \mathbf{C}$ NMR $\left(\mathrm{CDCl}_{3}, \delta\right): 31.0,42.3,55.6,112.1,113.8,115.1,116.2,118.8,121.7,128.3,130.7$, $132.5,140.4,146.3,148.4,154.0,156.7,158.7,162.8,194.0$. 
4d (74 \%). ${ }^{1} \mathbf{H}$ NMR $\left(\mathrm{CDCl}_{3}, \delta\right): 1.34$ (s, 9H); 1.68 (s, 6H); 6.87-7.42 (b, 17H); 7.78-7.80 (b, 2H)

${ }^{13} \mathbf{C}$ NMR $\left(\mathrm{CDCl}_{3}, \delta\right): 31.1,31.5,34.4,42.3,112.1,113.8,116.8,118.9,119.8,126.9,128.3$, 131.0, 132.5, 140.4, 146.3, 147.7, 152.8, 154.1, 158.7, 162.3, 194.0.

4e (76 \%). ${ }^{1} \mathbf{H}$ NMR $\left(\mathrm{CDCl}_{3}, \delta\right): 1.68(\mathrm{~s}, 6 \mathrm{H}) ; 6.85-7.50(\mathrm{~b}, 17 \mathrm{H}) ; 7.79-7.82(\mathrm{~b}, 2 \mathrm{H}){ }^{13} \mathbf{C}$ NMR $\left(\mathrm{CDCl}_{3}, \delta\right): 31.0,42.3,112.0,113.8,116.9,117.0 .118 .9,119.7,128.3,131.0,132.5,133.0$ 140.7, 146.6, 154.0, 158.0, 159.0, 162.1, 194.0.

4f (75 \%). ${ }^{1} \mathbf{H}$ NMR $\left(\mathrm{CDCl}_{3}, \delta\right): 1.67$ (s, 6H); 3.77 (s, 2H); 6.36-7.28 (b, $\left.17 \mathrm{H}\right) ; 7.78-7.80$ (b, 2H) ${ }^{13} \mathbf{C}$ NMR $\left(\mathrm{CDCl}_{3}, \delta\right): 31.0,42.3,106.7,109.9,111.4,112.1,113.8,117.1,118.9,128.3,130.6$, $131.1,132.4,140.4,146.3,148.3,154.0,156.4,158.7,161.9,194.1$.

\subsection{Co-polymerization of "Pre"-Functionalized Compound 2 with 3-methylphenol (3b) and} 4,4'-difluorobenzophenone via a "One-Pot", Two-step Approach, 4g.

A co-polymerization reaction was done by using a 50:50 mole ratio of "pre"functionalized compound $\mathbf{2}$ with $\mathbf{3 b}$ and $4,4^{\prime}$-difluorobenzophenone as the co-monomer. The copolymer synthesis was carried out using the same procedure used for the homo-polymerization reactions.

Step 1: In a $10 \mathrm{~mL}$ R.B flask, equipped with a stir bar, condenser and a nitrogen gas inlet, were placed $0.300 \mathrm{~g}(1.27 \mathrm{mmol})$ of 4', 3, 5-trifluorobenzophenone (2), $0.141 \mathrm{~g}(1.31 \mathrm{mmol})$ of 3methylphenol (3b), $2.0 \mathrm{~mL}$ of $N$-methylpyrrolidone (NMP) and $0.267 \mathrm{~g}(1.93 \mathrm{mmol})$ of potassium carbonate $\left(\mathrm{K}_{2} \mathrm{CO}_{3}\right)$. The reaction flask was immersed in a preheated oil bath and stirred vigorously at $110{ }^{\circ} \mathrm{C}$ until complete conversion to the desired mono-substituted product was achieved as determined via GC/MS analysis. 
Step 2: Into the same reaction flask were added $0.580 \mathrm{~g}(2.54 \mathrm{mmol})$ of bisphenol-A, $0.277 \mathrm{~g}$ (1.27 mmol) of 4,4'-difluorobenzophenone and $1.058 \mathrm{~g}(7.66 \mathrm{mmol})$ of $\mathrm{K}_{2} \mathrm{CO}_{3}$. The reaction temperature was raised to $185^{\circ} \mathrm{C}$ and maintained for 24 hours. The reaction was cooled to room temperature, precipitated from acidified distilled water and isolated by vacuum filtration to afford $1.03 \mathrm{~g}(85 \%)$ of a light brown solid. The solid was dissolved in $2.0 \mathrm{~mL}$ of $5 \%$ acetic acid in THF, precipitated from water and reverse precipitated from THF into hexane: isopropanol mixture (50:50), filtered, and dried to afford $0.873 \mathrm{~g}$ (72\%) of $\mathbf{4 g}$ as a light-brown solid. ${ }^{1} \mathbf{H}$ NMR $\left(\mathrm{CDCl}_{3}, \delta\right): 1.68-1.74(\mathrm{~b}, 6 \mathrm{H}) ; 2.35-2.38(\mathrm{~b}, 1.5 \mathrm{H}) ; 6.77-7.83(\mathrm{~b}, 17.5){ }^{13} \mathbf{C}$ NMR $\left(\mathrm{CDCl}_{3}\right.$,

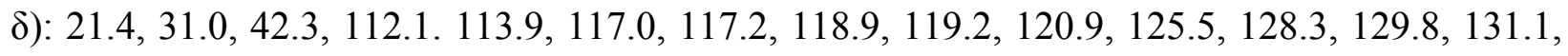
132.2, 132.5, 140.3, 140.4, 146.3, 146.7, 153.5, 154.0, 155.3, 158.7, 161.4, 162.1, 194.1, 194.3. 


\section{Results and Discussion}

\subsection{Monomer Synthesis and Characterization}

The synthesis of 4',3,5-trifluorobenzophenone, 1, was achieved via the one-step procedure outlined in Scheme 2. Room temperature reaction of commercially available 3,5difluorobenzoyl chloride with an excess of fluorobenzene, in the presence of aluminum chloride for 24 hours, afforded the desired compound, 1, in $62 \%$ yield after recrystallization from ethanol/water. Confirmation of the structure of $\mathbf{1}$ was provided by a combination of ${ }^{1} \mathrm{H},{ }^{13} \mathrm{C}$, and ${ }^{19}$ F NMR spectroscopy as well as elemental analysis.

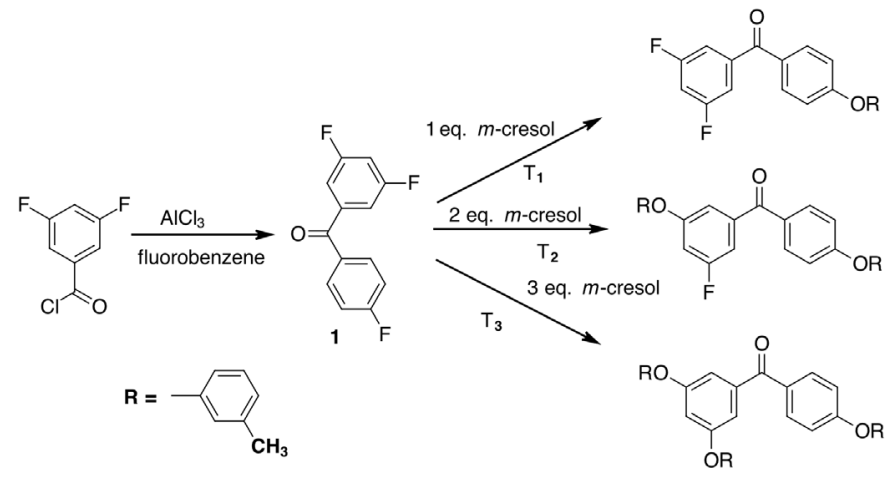

Scheme 2. Synthetic procedures for the synthesis of monomer $\mathbf{1}$ and model compounds, 2a-c. $\mathrm{T}_{1}=110{ }^{\circ} \mathrm{C}, \mathrm{T}_{2}=160^{\circ} \mathrm{C}, \mathrm{T}_{3}=185^{\circ} \mathrm{C}$. 


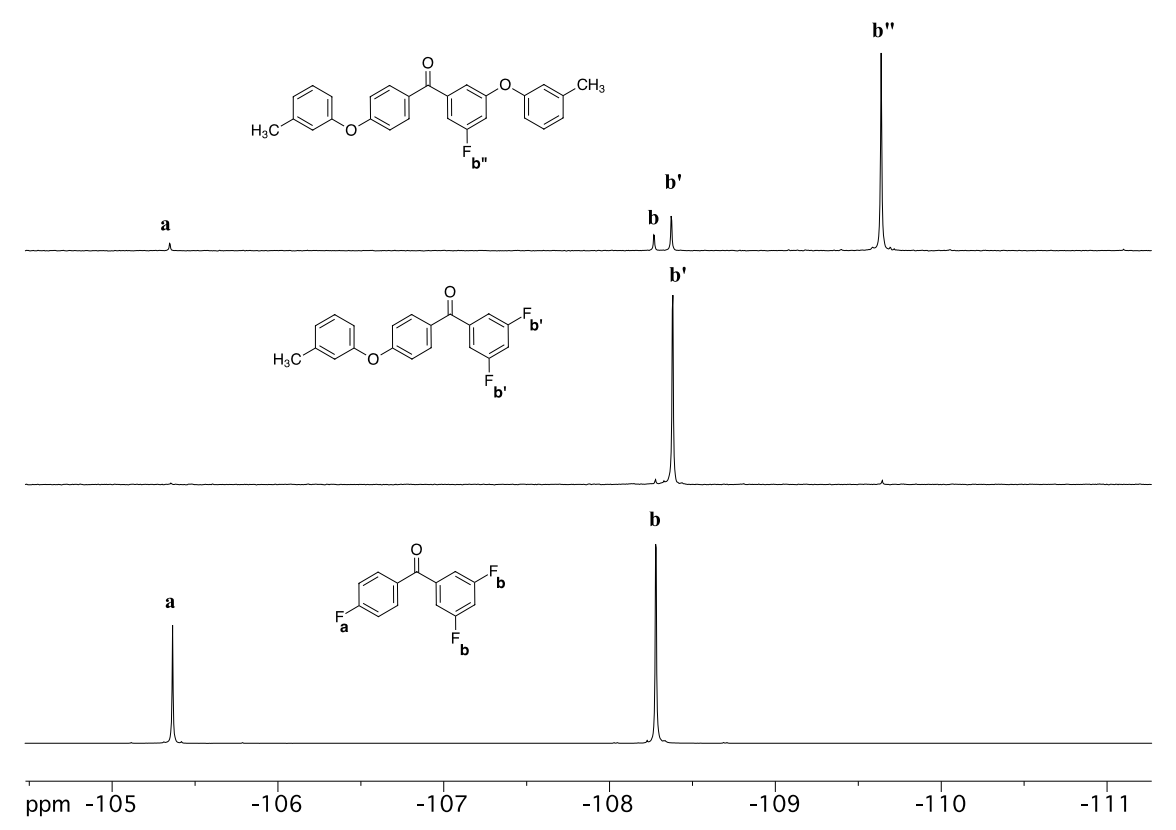

Figure 1. $376.5 \mathrm{MHz}{ }^{19} \mathrm{~F}$ NMR spectra $\left(\mathrm{DMSO}-d_{6}\right)$ of $\mathbf{1}, \mathbf{2 a}$, and 2b. 2a was prepared at a reaction temperature of $110^{\circ} \mathrm{C}$; synthesis of $\mathbf{2 b}$ was carried out at $160{ }^{\circ} \mathrm{C}$.

${ }^{19} \mathrm{~F}$ NMR spectroscopy has been reported as an excellent method for determining the relative reactivity of aryl fluorides towards NAS reactions. ${ }^{31}$ The ${ }^{19} \mathrm{~F}$ NMR chemical shift is a sensitive probe of the electron density on the carbon atom to which the fluorine is attached. In general, more electrophilic sites give rise to more downfield shifts in ${ }^{19} \mathrm{~F}$ NMR spectra, corresponding to higher reactivity in NAS reactions. The ${ }^{19} \mathrm{~F}$ NMR spectrum of $\mathbf{1}$ is presented in Figure 1 and it contains two unique signals, with an integration ratio of $1: 2$, present at -105.3 and -108.3 ppm, which are assigned to the para- and meta- fluorides, respectively. Since the signal for the para-fluoride was considerably downfield of that for the meta-fluorides it was expected to be significantly more reactive. As such, the reactivity of the three fluorides towards NAS 
reactions was probed via model reactions, using $m$-cresol as the nucleophilic reaction partner (Scheme 2).

The progress of the reactions was followed via a combination of gas chromatography/mass spectrometry (GC/MS) as well as DEPT90 ${ }^{13} \mathrm{C}$ and ${ }^{19} \mathrm{~F}$ NMR spectroscopy. The initial experiment, performed with one equivalent of $m$-cresol at $\mathrm{T}_{1}=110^{\circ} \mathrm{C}$, was designed to determine the selectivity for the para-position over the meta-positions. After 6 hours an aliquot was analyzed via GC/MS, which indicated nearly quantitative conversion to $2 \mathbf{a}$. Confirmation of the high selectivity, at $110^{\circ} \mathrm{C}$, for the formation of $\mathbf{2 a}$ was provided by the ${ }^{19} \mathrm{~F}$ NMR spectrum (Figure 1). The main signal in the spectrum, present at $-108.4 \mathrm{ppm}$, is assigned to the two fluorine atoms in $\mathbf{2 a}$, with the remaining two small signals, integrating at less than 1 $\%$, being assigned to the fluorine atoms in $\mathbf{1}$ and the disubstituted product, $\mathbf{2 b}(-109.6 \mathrm{ppm})$, respectively. The small upfield shift of the fluorine signals upon conversion from $\mathbf{1}$ to $\mathbf{2 a}$ indicates only a minor decrease in the reactivity of the remaining fluorine sites.

The synthesis of $\mathbf{2 b}$ was carried out with two equivalents of $m$-cresol at $160{ }^{\circ} \mathrm{C}$ for 10 hours and the ${ }^{19} \mathrm{~F}$ NMR spectrum of the product mixture indicates the presence of $2.2 \%$ unreacted 1, $6.6 \% \mathbf{2 a}$, and $91.2 \% \mathbf{2 b}$. Clearly, the selectivity for reaction at the para-position is decreased considerably at higher temperatures as evidenced by the presence of unreacted $\mathbf{1}$, thus the in situ functionalization reactions much be performed under carefully controlled conditions. As expected, the observed chemical shift for the remaining fluorine atom in $\mathbf{2 b}$ was shifted upfield to $-109.6 \mathrm{ppm}$, indicative of a lower reactivity toward NAS reactions, however, this value remains within the reactive range. 


\subsection{Polymer Synthesis}

In order to introduce functionality into the PEEK analogues a series of phenols was chosen, including phenol (3a), m-cresol (3b), $p$-methoxy phenol (3c), $t$-butyl phenol (3d), $p$ bromo phenol (3e), and 3-amino phenol (3f). Because the ${ }^{19} \mathrm{~F}$ NMR data from the model reactions indicated that a small percentage, $<1 \%$, of 1 remained in the reaction mixture when 1 equivalent of $m$-cresol was employed at $\mathrm{T}_{1}=110{ }^{\circ} \mathrm{C}$, the RRCP processes (Scheme 3) were carried out with a slight excess of the desired phenol, 1.03:1.0, (3a-f) to 1, respectively. The excess was used to ensure that all of $\mathbf{1}$ was converted to the desired " $\mathrm{B}_{2}$ " monomers in situ, thus minimizing any potential for the formation of branched or cross-linked materials. Any disubstituted product that formed would simply act as an end-capping agent, "B", a wellestablished method for limiting molecular weight in polycondensation reactions. The Carothers equation $(\mathrm{DP}=(1+\mathrm{r}) /(1-\mathrm{r})$ where $\mathrm{r}=0.97)$ afforded a degree of polymerization of $\sim 66$, which corresponds to molecular weights in excess of 10,000 Daltons, well in excess of the critical chain entanglement length for most PAE systems. ${ }^{32}$

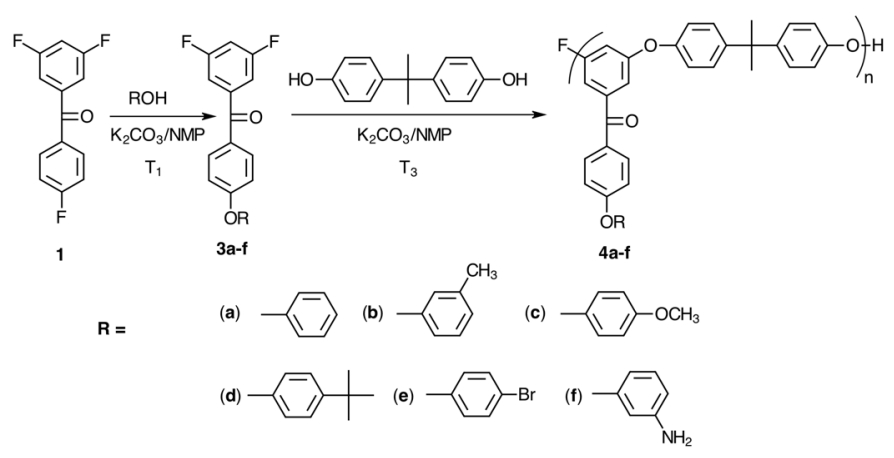

Scheme 3. Reactivity ratio controlled polycondensation reactions of $\mathbf{1}$ with various phenols and Bisphenol-A, under typical NAS conditions $\left(\mathrm{T}_{1}=110^{\circ} \mathrm{C} ; \mathrm{T}_{3}=185^{\circ} \mathrm{C}\right)$. 
Figure 2 displays the DEPT $90{ }^{13} \mathrm{C}$ NMR spectra of $\mathbf{1}$ and a sample taken from the reaction of $\mathbf{1}$ and $\mathbf{3 d}$ after 72 hours of reaction time at $110^{\circ} \mathrm{C}$. Since only carbon atoms with one $\mathrm{H}$ atom attached are observed in DEPT90 ${ }^{13} \mathrm{C}$ NMR spectra the number of signals is decreased considerably and the spectral assignments are quite straightforward. The spectrum of $\mathbf{1}$ clearly displays the splitting patterns resulting from the presence of the fluorine atoms on the two aromatic rings. The signals for carbon atoms $a$ and $b$ are observed as a triplet and doublet of doublets, present at 108.1 and 112.9 ppm, respectively, whereas the signals for carbon atoms $c$ and $d$ appear as doublets, present at 133.2 and $116.1 \mathrm{ppm}$, respectively.

After reaction of $\mathbf{1}$ with 1.03 equivalents of $\mathbf{3 d}$ significant changes in the spectrum are observed. The doublets that were previously assigned to carbon atoms $c$ and $d$ have been reduced to singlets present at 131.9 and $119.4 \mathrm{ppm}, c^{\prime}$ and $d^{\prime}$, respectively. Two new signals $(e$ and f), assigned to the 4-t-butylphenoxy group, can be seen at 116.4 and $126.5 \mathrm{ppm}$. The key observation is that the signals assigned to carbon atoms $a$ and $b$ remain unchanged after the reaction, confirming the ${ }^{19} \mathrm{~F}$ NMR results, which indicated nearly $100 \%$ selectivity for reaction at the para-position. The small signals, appearing slightly upfield of the peaks for $d$ and $e$ are assigned to the formation of the corresponding disubstituted product, a result of the slight excess of phenol used. As such, it can be concluded that the $t$-butyl functionalized $\mathrm{B}_{2}$-type monomer had been prepared in situ via a reactivity ratio controlled process. Similar results were observed for the remainder of the phenols utilized in Scheme 3. 


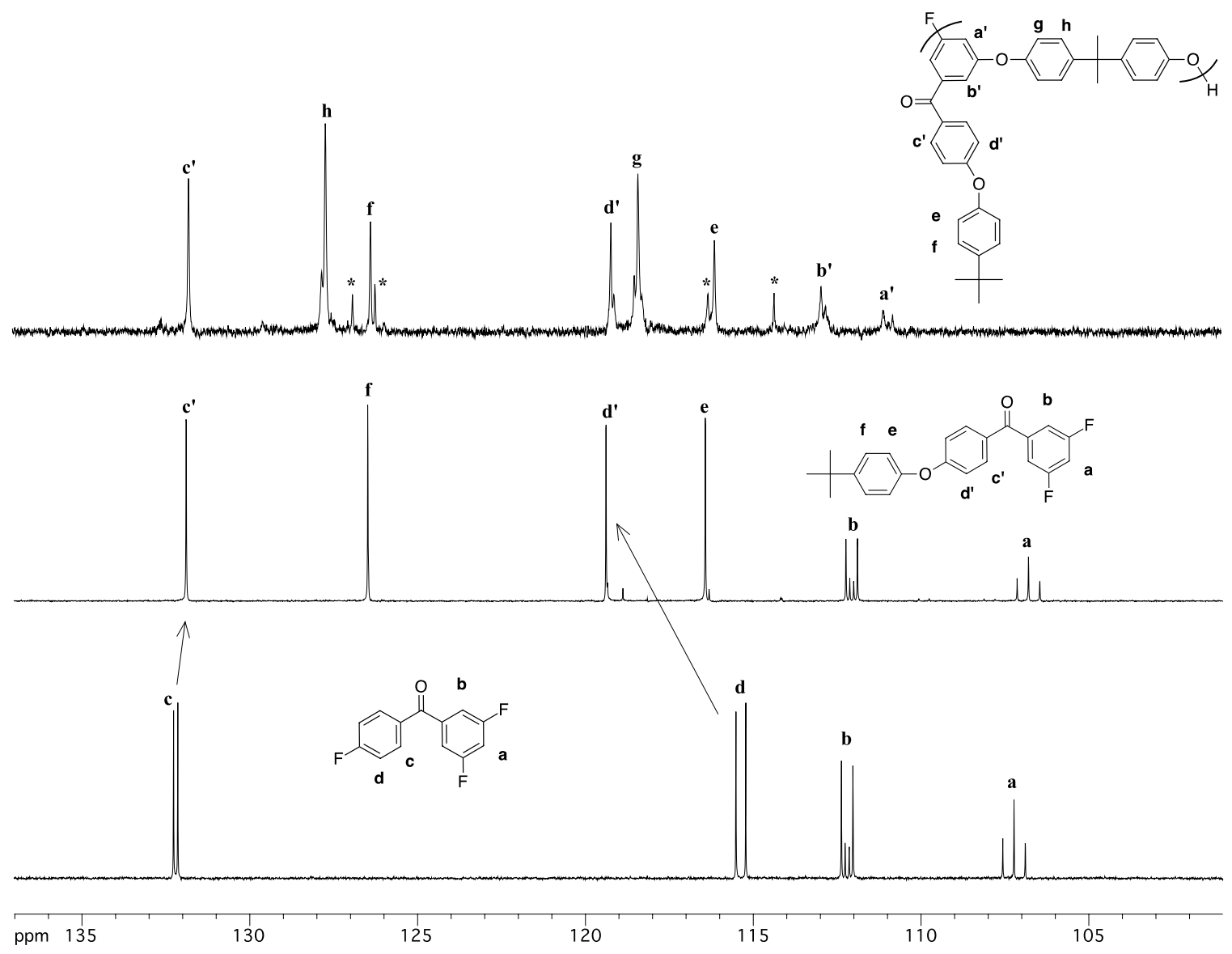

Figure 2. 75.5 MHz DEPT90 ${ }^{13} \mathrm{C}$ NMR spectra of $\mathbf{1}$, mono-substituted $\mathbf{1}$, and $\mathbf{4 d}$. The samples were dissolved in a mixture of NMP and DMSO- $d_{6}(0.2 \mathrm{ml} / 0.4 \mathrm{ml}$, respectively).

In the second step of the reaction, Bisphenol-A was added to the reaction flask and the mixture was heated to $185{ }^{\circ} \mathrm{C}$ for 24 hours. The polymers were precipitated from slightly acidified $(\mathrm{pH} \sim 5-6)$ distilled water, isolated via vacuum filtration and dried. The polymers showed excellent solubility in tetrahydrofuran (THF), chloroform, dichloromethane (DCM) and $\mathrm{N}$-methyl-2-pyrrolidone (NMP), but were insoluble in dimethylsulfoxide (DMSO), methanol $(\mathrm{MeOH})$, ethanol (EtOH), and isopropanol (IPA). 
The DEPT90 ${ }^{13} \mathrm{C}$ NMR spectrum of polymer $4 \mathbf{d}$ is shown in Figure 2 and clearly indicates that the fluorine atoms in the meta-positions of $\mathbf{3 d}$ have been displaced as the unique triplet and doublet of doublets, arising from carbon atoms $a$ and $b$, are no longer present. In their place are two broad signals, labeled $a^{\prime}$ and $b^{\prime}$, which are shifted slightly upfield. Two new signals, assigned to carbon atoms $g$ and $h$ in the Bisphenol-A component, are present at 118.4 and 127.7 , respectively. In addition to all of the expected signals, a series of peaks (labeled with an asterisk) that can be described as shadows of the main signals is present in the spectrum. In previous work with 3,5-difluoro aromatic systems, a tendency to form a significant quantity of cyclic species, relative to the desired linear polymers, was observed, however, they could be

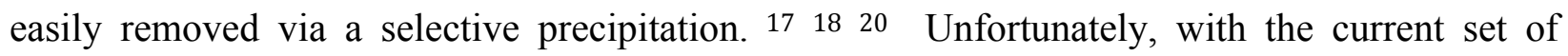
polymers, the solubility differences between the linear and presumably cyclic species were insufficient to allow their separation. As such, the additional signals present in the spectrum of 4d most likely represent the associated cyclic species.

\subsection{Molecular Weight Determination}

The weight average molecular weights, $\mathrm{M}_{\mathrm{w}}$, of polymers $4 \mathbf{a}-\mathbf{f}$ were determined via SEC using the light scattering detector while the dispersities were calculated from the refractive index detector; the data is summarized in Table 1. All of the polymers possessed $\mathrm{M}_{\mathrm{w}}$ values near or above 20,000 Daltons (Da) with dispersity values well in excess of 2.0 in all cases. The highest $M_{w}$ value (69,000 Da) was for polymer 4a, while the lowest $M_{w}$ value (18,700 Da) was observed for the bromo-substituted polymer, 4e. The high dispersity values are a direct result of the inability to separate the linear polymers from the low molecular weight, presumably cyclic species (see Figure 3). The SEC traces (RI signal) for polymers $\mathbf{4 b}$ and $\mathbf{4 d}$ are shown in Figure 3 
and clearly indicate that the reprecipitation process was not very effective in removing the low molecular weight species.

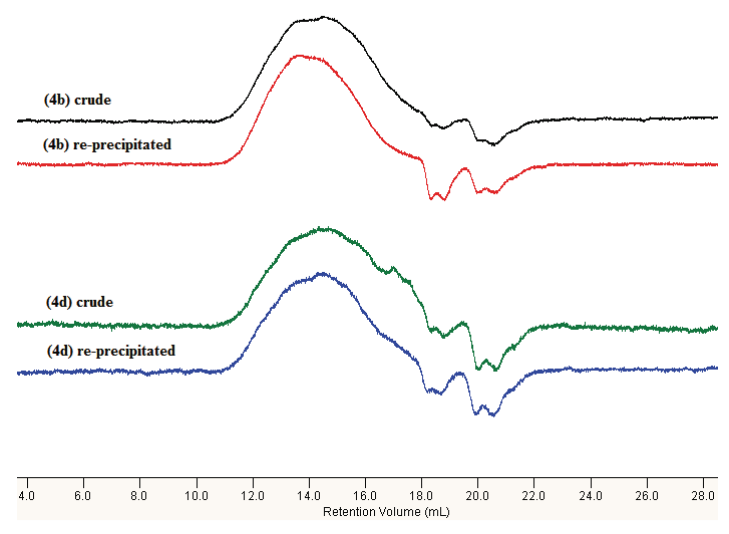

Figure 3. SEC (RI signal) traces of crude and re-precipitated polymers, $\mathbf{4 b}$ and $\mathbf{4 d .}$

Table 1. Percentage yield, molecular weight, dispersity and thermal properties for polymers prepared from monomers 1, phenols 3a-f, and Bisphenol-A.

$\begin{array}{cccccc}\text { Polymer } & \text { \% yield } & \left.\mathbf{M}_{\mathbf{w}}{ }^{\mathbf{a}} \mathbf{( D a}\right) & \underline{\underline{\text { Dispersity }}} & \mathbf{T}_{\mathbf{g}}\left({ }^{\circ} \mathbf{C}\right) & \underline{\underline{\mathbf{T}}} \underline{\mathbf{d} \mathbf{5} \%}\left({ }^{\circ} \mathbf{C}\right) \\ \mathbf{4 a} & 70 & 69,000 & 10.5 & 122 & 459 \\ \mathbf{4 b} & 78 & 44,000 & 5.1 & 108 & 398 \\ \mathbf{4 c} & 80 & 45,800 & 9.1 & 112 & 380 \\ \mathbf{4 d} & 74 & 47,000 & 5.6 & 127 & 400 \\ \mathbf{4 e} & 76 & 18,700 & 7.5 & 113 & 456 \\ \mathbf{4 f} & 75 & 39,300 & 5.0 & 136 & 457 \\ \mathbf{4 g}^{\mathbf{c}} & 72 & 25,300 & 2.8 & 112 & 448\end{array}$
a. Determined via from light scattering detector in SEC analysis.
b. Determined from the refractive index signal and conventional calibration.
c. 50:50 Copolymer prepared from 1, 3b, Bisphenol-A, and 4,4'-difluorobenzophenone. 
To further explore these observations, a copolymer was prepared by first reacting 1 with 3b, followed by the addition of Bisphenol-A and 4,4'-difluorobenzophenone. The ratio of $\mathbf{1}$ to 4,4'-difluorobenzophenone was 1:1, which should lead to a 50:50 copolymer, $4 \mathbf{g}$, of the functionalized and non-functionalized repeat units. Interestingly, even though polymer $\mathbf{4 g}$ had a $\mathrm{M}_{\mathrm{w}}$ value of $25,300 \mathrm{Da}$, it possessed a considerably lower dispersity value, 2.8 , than any of the other polymers. This result lends some credence to the high dispersity values of polymers 4a-f being a result of the presence of cyclic species formed with the 3,5 orientation of the fluoride leaving groups in $\mathbf{1}$.

\subsection{Thermal Properties}

The thermal properties of polymers 4a-g were evaluated by a combination of Thermogravimetric Analysis (TGA) and Differential Scanning Calorimetry (DSC). Under a nitrogen atmosphere the polymers exhibited $5 \%$ weight loss temperatures $\left(\mathrm{T}_{\mathrm{d}-5 \%}\right)$ ranging from 380 to $459{ }^{\circ} \mathrm{C}$ as summarized in Table 1 . The TGA thermogram for polymer $\mathbf{4 f}$ is shown in Figure 4 and is representative of all of the polymers in the series. There is a slight weight loss starting near $300^{\circ} \mathrm{C}$, followed by a signal step degradation, presumably involving both the side group and backbone. The initial weight loss present in the TGA traces of all of the polymers may be ascribed to the presence of the cyclic species, which might be less stable, under high temperature conditions, than are the higher molecular weight, linear species. The thermal stability also depended on the nature of the group present on the pendent phenoxy moiety. For example, while the phenyl group alone (4a) had a $\mathrm{T}_{\mathrm{d}-5 \%}$ of $459{ }^{\circ} \mathrm{C}$ the $t$-butyl phenoxy group (4d) imparted a considerably lower stability with a $\mathrm{T}_{\mathrm{d}-5 \%}$ of only $400{ }^{\circ} \mathrm{C}$. The amino $(\mathbf{4 f})$ and bromo (4e) functionalized polymers displayed a high level of thermal stability with $T_{d-5 \%}$ values of 457 and $456^{\circ} \mathrm{C}$, respectively. 


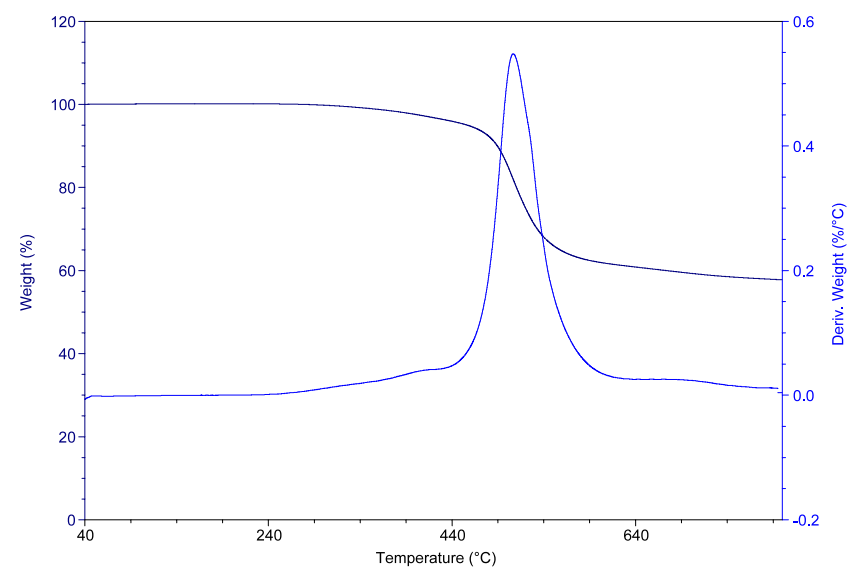

Figure 4. Thermograms, weight percentage and first derivative of weight percent, for polymer 4f, at a heating rate of $10{ }^{\circ} \mathrm{C} / \mathrm{min}$., under nitrogen.

The DSC analyses indicated that the entire series, $\mathbf{4 a - j}$, were completely amorphous as only glass transition temperatures, $\mathrm{T}_{\mathrm{g}}$, were observed in heating scans up to $350{ }^{\circ} \mathrm{C}$. The DSC traces of polymers $\mathbf{4 a - g}$ are given in Figure 5 and show a relatively narrow range in the glass transition temperature $\left(\mathrm{T}_{\mathrm{g}}\right)$ values, 108 to $136{ }^{\circ} \mathrm{C}$, despite the difference in pendent group structure. Because the backbone of the polymers remains the same, regardless of what functional group is installed on the pendent phenoxy group, the change in $T_{g}$ value is an indication of the steric constraints, free volume effects, and intermolecular forces imparted by each specific group. For example, the phenol system (4a) has a $\mathrm{T}_{\mathrm{g}}$ of $122{ }^{\circ} \mathrm{C}$ while the $m$-cresol polymer (4b) has a slightly lower $\mathrm{T}_{\mathrm{g}}$ of $108{ }^{\circ} \mathrm{C}$, most likely due to increased free volume with the methyl group located in the meta-position. The amino substituted polymer (4f) displayed a somewhat higher $\mathrm{T}_{\mathrm{g}}, 136^{\circ} \mathrm{C}$, indicating that the intermolecular forces, inherent to the amino group, provide a slight enhancement to the $\mathrm{T}_{\mathrm{g}}$, relative to the phenyl group itself. 


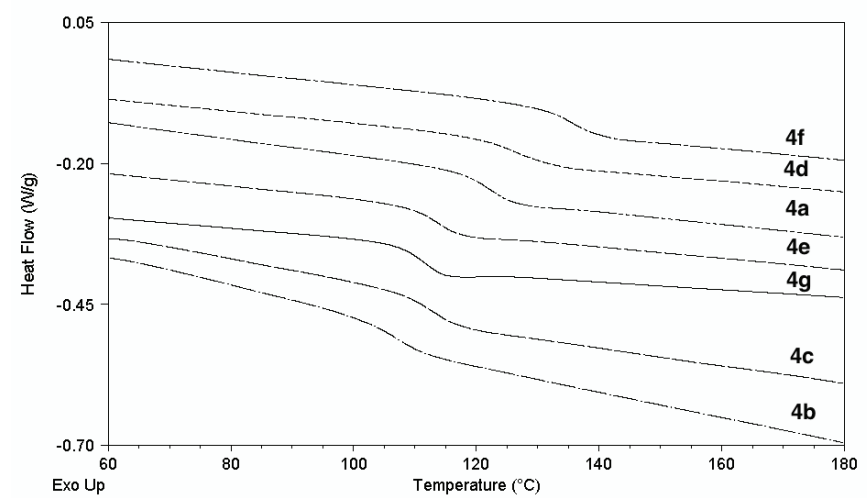

Figure 5. Differential scanning calorimetry traces for polymers $\mathbf{4 a - f}$, as well as the copolymer, $\mathbf{4 g}$, under a nitrogen atmosphere, at a heating rate of $10^{\circ} \mathrm{C} / \mathrm{min}$.

\section{Conclusions}

A "one-pot", two-step method for the synthesis of functional group bearing poly(ether ether ketone) analogues has been developed, termed reactivity ratio controlled polycondensation, RRCP. The method is based on the reactivity differences, toward NAS reactions, of the three aryl fluoride groups present in 3,5,4'-trifluorobenzophenone, 1 . The reactivity of the three sites was probed via ${ }^{19} \mathrm{~F}$ NMR spectroscopy, as well as model reactions, which showed that the parafluorine was considerably more reactive than the fluorine leaving groups located in the metapositions. The differences in reactivity were exploited by reacting $\mathbf{1}$ with a series of phenols to generate functional $\mathrm{B}_{2}$ monomers in situ that were then reacted with Bisphenol-A to afford the corresponding linear poly(arylene ether)s. The polymer formation was accompanied by the formation of presumably cyclic materials that could not be removed via precipitation processes, thus the dispersity values were quite high. The polymers displayed relatively good high temperature stability with most $5 \%$ weight loss temperatures approaching or in excess of 400 
${ }^{\circ} \mathrm{C}$. All of the polymers were completely amorphous, displaying only glass transition temperatures in a tight range from 108 to $136{ }^{\circ} \mathrm{C}$. Current efforts are directed at the synthesis of semi-crystalline analogues of the materials described herein.

\section{Acknowledgements}

This material is based upon work supported by the National Science Foundation under CHE1307117. Dr. Tanya Young from the NMR Center at the Ohio State University Department of Chemistry is acknowledged for her assistance with ${ }^{19} \mathrm{~F}$ NMR spectroscopy.

\section{References}

(1) Hay, A. S. J. Polym. Sci. Part A: Polym. Chem. 1998, 36, 505.

(2) Teasley, M. F.; Hsiao, B. S. Macromolecules 1996, 29, 6432.

(3) Attwood, T. E.; Dawson, P. C.; Freeman, J. L.; Hoy, R. J.; Rose, J. B.; Staniland, P. A. Polymer 1981, 22, 1096.

(4) Johnson, R. N.; Farnham, A. G.; Clendinning, R. A.; Hale, W. F.; Merriam, C. N. J. Polym. Sci.: Part A-1: Polym. Chem. 1967, 5, 2375.

(5) Atwood, T. E.; Barr, D. A.; Feasey, G. G.; Leslie, V. J.; Newton, A. B.; Rose, J. B. Polymer 1977, 18, 354.

(6) Wiles, K. B.; Wang, F.; McGrath, J. E. J. Polym. Sci. Part A: Polym. Chem. 2005, 43, 2964. 
(7) Wang, L.; Meng, Y. Z.; Wang, S. J.; Hay, A. S. J. Polym. Sci.: Part A: Polym.

Chem. 2004, 42, 1779.

(8) Xu, J.; Meng, Y. Z.; Wang, J. S.; Hay, A. S. J. Polym. Sci. Part A: Polym. Chem. 2007, 45, 262.

(9) Wang, F.; Chen, T.; Xu, J. Macromol. Chem. Phys. 1998, 199, 1421.

(10) Cheng, L.; Ying, L.; Feng, J.; Wang, C. Y.; Li, J. L.; Xu, Z. J. Polym. Sci. Part A: Polym. Chem. 2007, 45, 1525.

(11) Connell, J. W.; Smith, J., J. G.; Hergenrother, P. M. Polymer 1995, 36, 5.

(12) Connell, J. W.; Smith Jr., J. G.; Hedrick, J. L. Polymer 1995, 36, 13.

(13) Riley, D. J.; Gungor, A.; Srinivasan, S. A.; Sankarapandian, M.; Tchatchoua, C.; Muggli, M. W.; Ward, T. C.; McGrath, J. E. Polym. Eng. Sci. 1997, 37, 1501.

(14) Smith Jr., J. G.; Webster, H. F.; Gungor, A.; Wightman, J. P.; McGrath, J. E. High Perf. Polym. 1991, 3, 211.

(15) Lin, Q.; Long, T. E. J. Polym. Sci.: Part A: Polym. Chem. 2000, 38, 3736.

(16) Bernal, D. P.; Bankey, N. B.; Cockayne, R. C.; Fossum, E. J. Polym. Sci.: Part A: Polym. Chem. 2002, 40, 1456.

(17) Kaiti, S.; Himmelberg, P.; Williams, J.; Abdellatif, M.; Fossum, E. Macromolecules 2006, 44, 7909.

(18) van Beek, D.; Fossum, E. Macromolecules 2009, 42, 4016. 
(19) Tienda, K.; Yu, Z.; Constandinidis, F.; Fortney, A.; Feld, W. A.; Fossum, E. J. Polym. Sci. Part A: Polym. Chem. 2011, 49, 2908.

(20) Selhorst, R.; Fossum, E. Polymer 2013, 54, 530.

(21) Koch, T.; Ritter, H. Macromolecules 1995, 28, 4806.

(22) Xiang, P.; Robertson, G. P.; Guiver, M. D.; Mikhailenko, S. D.; Wang, K.; Kaliaguine, S. J. Memb. Sci. 2004, 229, 95.

(23) Wang, F.; Roovers, J. Macromolecules 1993, 26, 5295.

(24) Gao, X.; Wang, R.; Zhang, A. Mater. Lett. 2007, 61, 3647.

(25) Parthiban, A.; Le Guen, A.; Yangsheng, Y.; Hoffmann, U.; Klapper, M.; Mullen, K. Macromolecules 1997, 30, 2238.

(26) Huang, X.; Chen, Z.; Lin, P.; Huang, J.; Chen, W. Polym. Int. 2009, 58, 715.

(27) Yameen, B.; Alvarez, M.; Azzaroni, O.; Jonas, U.; Knoll, W. Langmuir 2009, 25, 6214.

(28) Diez-Pascual, A. M.; Martinez, G.; Gomez, M. A. Macromolecules 2009, 42, 6885.

(29) Fortney, A.; Fossum, E. Polymer 2012, 53, 2327.

(30) Raghavapuram, S. M.S. Thesis, Wright State University, 2009.

(31) Carter, K. R. Macromolecules 1995, 28, 6462. 
(32) Wang, S.; McGrath, J. E. In Synthetic Methods in Step-Growth Polymers; Rogers, M. W., Long, T. E., Eds.; John Wiley \& Sons: New York, 2003. 


\section{Captions for Figures}

Figure 1. 376.5 $\mathrm{MHz}{ }^{19} \mathrm{~F}$ NMR spectra $\left(\mathrm{DMSO}-d_{6}\right)$ of $\mathbf{1}, \mathbf{2 a}$, and $\mathbf{2 b}$. 2a was prepared at a reaction temperature of $110^{\circ} \mathrm{C}$; synthesis of $\mathbf{2 b}$ was carried out at $160{ }^{\circ} \mathrm{C}$.

Figure 2. $75.5 \mathrm{MHz}$ DEPT90 ${ }^{13} \mathrm{C}$ NMR spectra of $\mathbf{1}$, mono-substituted $\mathbf{1}$, and $\mathbf{4 d}$. The samples were dissolved in a mixture of NMP and DMSO- $d_{6}(0.2 \mathrm{ml} / 0.4 \mathrm{ml}$, respectively).

Figure 3. SEC (RI signal) traces of crude and re-precipitated polymers, $\mathbf{4 b}$ and $\mathbf{4 d}$.

Figure 4. Thermograms, weight percentage and first derivative of weight percent, for polymer 4f, at a heating rate of $10{ }^{\circ} \mathrm{C} / \mathrm{min}$., under nitrogen.

Figure 5. Differential scanning calorimetry traces for polymerss 4a-f, as well as the copolymer, under a nitrogen atmosphere, at a heating rate of $10^{\circ} \mathrm{C} / \mathrm{min}$. 


\section{Graphical Abstract}

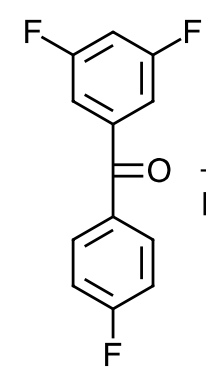

BB'B" Monomer

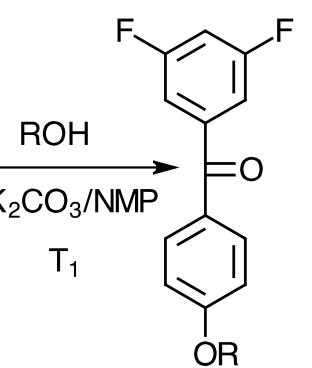

in situ

Functional B'B" Monomer

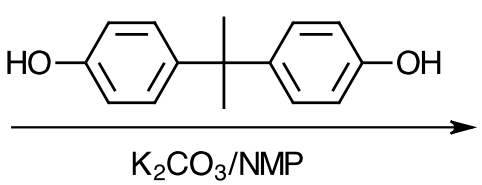

$\mathrm{T}_{3}$

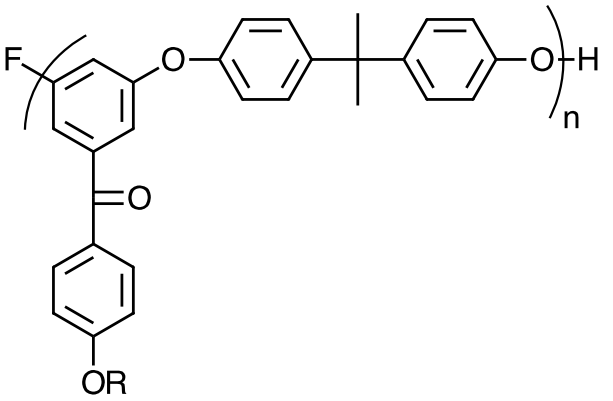

Functional PEEK Analogue 